\title{
Monitoring the occurrence of genetically modified oilseed rape growing along a Japanese roadside: 3-year observations
}

\author{
Toru NiShIZAWA, Nobuyoshi NAKAJIMA*, Mitsuko AONO, Masanori TAMAOKI, Akihiro KUBO and Hikaru SAJI \\ Environmental Biology Division, National Institute for Environmental Studies, 16-2 Onogawa, Tsukuba 305-8506, Japan
}

\begin{abstract}
Monitoring for escape of genetically modified (GM) oilseed rape (Brassica napus) during transport can be performed by means of roadside evaluations in areas where cultivation of this GM crop is not conducted, such as in Japan. We performed a survey of oilseed rape plants growing along a 20-km section of Japan's Route 51, one of the main land transportation routes in central Japan for imports of GM oilseed rape from the Port of Kashima into Keiyo District. Oilseed rape plants were found each year, but the number of plants varied substantially during the three years of our study: 2162 plants in 2005, 4066 in 2006, and only 278 in 2007. The low number in 2007 was probably caused by roadwork. Herbicide-resistant individuals were detected in the three consecutive years $(26,8$, and 5 individuals with glyphosate resistance), but glufosinate-resistant plants (9 individuals) were detected only in 2005. The roadside plants occurred mainly along the inbound lane from Kashima to Narita. These plants are likely to have their origin in seeds spilled during transportation of cargo from the port, since there are no potential natural seed source plants for $B$. napus near Route 51 . This is the first detailed report on the transition and distribution of herbicide-resistant oilseed rape plants following loss and spillage along Japanese roads.
\end{abstract}

Keywords: Brassica napus / genetically modified crop / loss and spillage / oilseed rape / roadside population / seed dispersal by vehicles

\section{INTRODUCTION}

Genetically modified (GM) crops have been grown in many countries, and the area cultivated with these crops increases yearly, reaching more than 120 million ha by 2007 . The majority of GM crops are used as animal feed or processed for food (ISAAA, 2007). Most commercially-released GM plants are herbicide-, insect-, pest-, or disease-resistant crop plants, for example, showing resistance to the herbicides glyphosate and glufosinate, lepidopteran larvae, or diseases caused by plant viruses (ISAAA, 2007; Snow et al., 2005). Expansion of the cultivation of GM crops has raised concerns about the environmental consequences of their escape from arable fields, hybridization with wild relatives, and introgression of transgenes into the genomes of wild plant populations (e.g., Lu, 2008; Stewart, 2005; Stewart et al., 2003; Warwick et al., 2003). In addition, the likelihood that a GM crop might escape is increased by loss and spillage of GM crops during transportation.

*Corresponding author: naka-320@nies.go.jp
Human activity has often been associated with plant dispersal (Hodkinson and Thompson, 1997), especially the transport of seeds by vehicles, which are an efficient dispersal vector for many plant species (von der Lippe and Kowarik, 2007a; Yoshimura et al., 2006; Zwaenepoel et al., 2006). Crawley and Brown (2004) found an asymmetrical distribution of oilseed rape (Brassica napus L.) along roads. Spontaneous oilseed rape populations were significantly more abundant in lanes leading to an oilseed processing factory than along the side of roads leading away from the factory. They assumed that seeds spilled from transport vehicles were the main seed source for the oilseed rape populations that became established along the road (Crawley and Brown, 1995, 2004).

Routes of unintended escape of crops and their occurrence along roadsides have been studied for more than a decade in some crop species for which GM varieties have been commercialized (Gray and Raybould, 1998). For example, von der Lippe and Kowarik (2007b) showed that traffic-mediated long-distance dispersal of conventional non-GM seeds provides a significant escape route for arable crops under cultivation in a region. They found that 
the most abundant crop species in seed samples captured in traps established in two motorway tunnels in Germany were wheat (Triticum aestivum L.), cereal rye (Secale cereale L.), and oilseed rape. Depositions of seeds of these crops were associated with the direction of traffic flow. As in the report by Crawley and Brown (2004), seed spillage and dispersal by vehicles was the likely origin of these crops, since there were no potential seed sources near the tunnels.

The annual Japanese importation of four crops (corn, soybean, cotton, oilseed rape) that presumably contain seeds of GM plants exceeds 23 million $t$ of seeds, of which about $10 \%$ is oilseed rape (ISAAA, 2006). Imported oilseed rape is discharged at several main ports (Kashima, Chiba, Yokohama, Shimizu, Nagoya, Yokkaichi, Sakai-Senboku, Kobe, Uno, Mizushima, KitaKyusyu, and Hakata) and transported to an inland processing factory (by vehicles) along several main national roads. Von der Lippe and Kowarik (2007b) noted the necessity to elucidate losses of GM crops during transport by monitoring the edges of roads and adjacent areas along transportation routes, as these corridors are focal points for monitoring of GM plants in case loss and spillage need to be controlled. This is particularly important for oilseed rape, since this crop is not cultivated commercially in Japan.

Although roads have been implicated as an important escape corridor for GM oilseed rape, this phenomenon remains poorly studied in Japan. In our previous research, we reported the spontaneous occurrence of herbicideresistant GM oilseed rape that had been disseminated as seeds along roadsides in Japan during transport from several major ports (Aono et al., 2006; Saji et al., 2005). These studies were based on a 1-year sampling, thus the research provided no knowledge about the fate of these herbicide-resistant plants in future years. Oilseed rape can exhibit highly fluctuating population dynamics outside cultivated fields (Crawley and Brown, 1995, 2004; Pessel et al., 2001) and potentially cultivable fields (Gruber et al., 2004; Lutman, 1993). Therefore, more detailed information collected over a longer period was required to reveal the potential invasiveness and persistence of GM oilseed rape under the conditions along Japanese roads.

In the present study, we performed roadside surveys to detect the appearance of oilseed rape plants along Japan's Route 51 for a 3-year period $(2005,2006$, and 2007). Route 51 is one of the main transportation routes in central Japan for imported oilseed rape from the Port of Kashima to Keiyo District. The presence of herbicideresistant individuals of oilseed rape was confirmed at several sites along this road by our preliminary research (Saji et al., 2005). In addition, we carried out more intensive fixed-route observation along a $20-\mathrm{km}$ part of this road
(Fig. 1). This is the first report on the detailed distribution and the transition of herbicide-resistant oilseed rape plants following loss and spillage along a Japanese road.

\section{RESULTS AND DISCUSSION}

\section{Roadside oilseed rape plants along Route $\mathbf{5 1}$}

We recorded oilseed rape plants at 1147 and 1336 sites in the monitored zone in 2005 and 2006, respectively, but the number decreased substantially to 256 sites in 2007 (Tab. 1). We counted all individuals found growing along the road, but there were some sites where many seedlings were concentrated, such as in square ponds, drains, and gutters (Fig. 2A). We treated these dense sites (typically about $50 \mathrm{~cm}^{2}$ ) as a single site and counted all individuals at that site. We defined a minimum interval between dense sites of about $30 \mathrm{~cm}$. The number of individuals growing along the road in the monitored zone varied widely among the years, with 2162 individuals in 2005, 4066 in 2006, and 278 in 2007, which is the same order of abundance as the number of sites (Tab. 1). Most individuals were found to grow in a chink between the concrete curbstone and the asphalt road or sidewalk, but some were growing in vacant lots or flowerbeds (Figs. 2 and $3 \mathrm{~A}$ ).

Each $1-\mathrm{km}$ section of the monitoring route was defined as a segment, and each segment was numbered according to the distance from the starting point. The number of plants in a segment, which reveals variations in the occurrence of the plants within narrow intervals, fluctuated widely among the three years (Fig. 4).

In segment \#15 in 2006, the plants were extremely abundant as a result of the formation of a gutter population, where the mud that accumulated at the bottom of the gutter provided good conditions for seedling establishment. Because it was difficult to count all individuals at this site, we divided it into 4-m subsets and counted all individuals within a $1 \times 1-\mathrm{m}$ area of sampling points located throughout the community, separated by $4 \mathrm{~m}$; we then estimated the total number of individuals by extrapolation from these samples. The total length of the gutter population in segment \#15 was about $150 \mathrm{~m}$. The gutter population was located in a dip in the road, and the depression was lowest in the dense zone of oilseed rape. The concrete gutter was about $30 \mathrm{~cm}$ deep and wide, and was slightly lower than the road surface. In this part of the study area, Route 51 passes through a rice field and its base is raised several meters above the surrounding land (Fig. 3B). The dominant plant species covering the slope between the road surface and the surrounding land were tall goldenrod (Solidago altissima L.), kudzu vine (Pueraria lobata (Willd.) Ohwi), and wormwood (Artemisia princeps Pamp.), but B. napus was not found. 
Spontaneous occurrence of GM oilseed rape in Japan

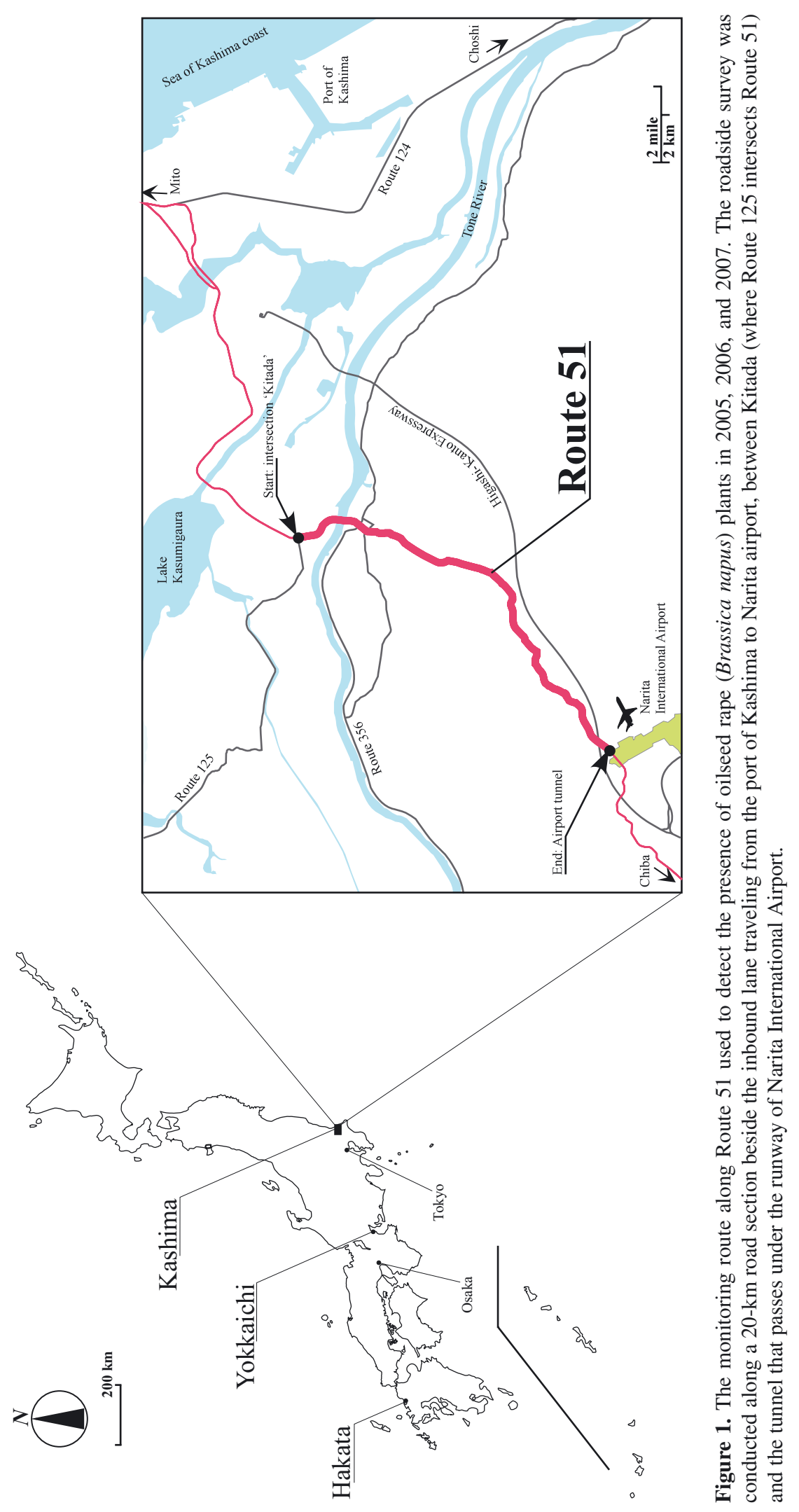


Table 1. Number of sites containing oilseed rape, total number of plants at these sites, and number of herbicide-resistant individuals detected along Route 51 from 2005 to 2007. The roadside surveys were conducted at the time of flowering of Brassica species, from mid-April to early-June.

\begin{tabular}{lccc}
\hline & \multicolumn{3}{c}{ Year } \\
\cline { 2 - 4 } & 2005 & 2006 & 2007 \\
\hline Total number of individuals & 2162 & $4066^{2}$ & 278 \\
Number of sampling sites & 1147 & 1336 & 256 \\
Sites with multiple individuals $^{1}$ & 126 & 297 & 5 \\
Number of transgenic plants & 35 & 8 & 5 \\
Glyphosate-resistant plants & 26 & 8 & 5 \\
Proportion of glyphosate-resistant plants (\%) & 1.20 & 0.20 & 1.80 \\
Glufosinate-resistant plants & 9 & 0 & 0 \\
Proportion of glufosinate-resistant plants (\%) & 0.42 & 0 & 0 \\
\hline
\end{tabular}

${ }^{1}$ Number of sites where more than one plant was detected.

${ }^{2}$ Estimated value. Because of the exceptionally high density of plants in segment \#15 in 2006, we counted all the plants in small samples and extrapolated this result to the total area. See the Results and Discussion for details.

The gutter in segment \#15 is presumed to be a location where seeds carried from outside the area would have easily accumulated. An influx of spilled seeds into the gutter is likely to be the source of this large population. However, secondary dispersal may also occur, such as the transport of seeds by moving water during rainy periods. This would contribute to the formation of gutter populations, because seeds on or near the road surface would naturally be washed into the gutters.

The mud habitat at the gutter bottom appears unlikely to support the oilseed rape population in the long term, since the number of plants in this segment decreased to about $2 \%$ of the 2006 level the following year. In Japan, some cultivated Brassica plants germinate in autumn and overwinter as a rosette. Brassica napus plants growing in central Honshu, Japan, begin to flower from late March to mid-April, and their siliques mature over the summer. Some early-matured seeds of $B$. napus begin to fall from early May to June, but most are released during the early summer. Japan has a temperate climate with two long rainy periods: one from mid-June to late July and another from mid-September to early October. The majority of the mud that had accumulated at the bottom of the gutter over the year as well as mud-buried seeds would be swept away by the water flow produced by strong autumn rains. Therefore, additional input of seeds that occurred between the end of the autumn rain and the following spring likely contributed to the formation of the gutter population.

High variability in the presence of oilseed rape, such as that observed in segment \#15, was also detected in segments \#5 and \#12 from 2005 to 2006 (Fig. 4). Relatively large numbers of individuals (259 in segment \#5 and 252 in segment \#12) were detected in 2005, but the numbers decreased to less than $1 \%$ (2 plants in segment \#5) and less than 25\% (61 plants in segment \#12) of these totals the following year. Therefore, the existence of a gutter does not seem to be necessary for the formation of large oilseed rape populations: in these segments the populations were growing in a chink between the concrete curbstone and the asphalt road or sidewalk. These results suggest that oilseed rape populations may appear, if suitable space provides seeds with a chance to survive.

In the roadside habitats along Route 51 , we did not detect massive dispersal or long-term persistence of oilseed rape populations. However, the number of plants that we detected along the road changed dramatically among years. In some areas of Route 51 inside Chiba Prefecture, road improvement work (restoration of the asphalt pavement, widening of sidewalks, and construction of flowerbeds) was performed. For example, during the roadside survey in 2006, we encountered roadwork that involved the widening of sidewalks in some areas of segments \#7 and \#8. The numbers of oilseed rape plants that were detected in these segments (61 in segment \#7 and 92 in segment \#8) decreased to less than $30 \%$ of this total in the following year (17 plants in segment \#7 and 11 plants in segment \#8). Roadwork, and especially operations such as the exfoliation of asphalt or the replacement of sand, would greatly affect the survival and the persistence of plants along the roadside. Indeed, where road improvement work was carried out in the previous year, chinks between the curbstone and the asphalt were closed off and few plants became established.

\section{Detection and transition of herbicide-resistant plants}

GM oilseed rape plants were detected in each of the three years, but the number decreased each year (Tab. 1, Fig. 5A). Glyphosate-resistant individuals were detected in all three monitoring years, with 26 surveyed in 2005 , 8 in 2006, and 5 in 2007. Nine glufosinate-resistant individuals were detected, but only in 2005 . On the west coast of Canada, the frequency of herbicide-resistant oilseed rape found along transportation routes was similar to the rate of GM oilseed rape that was adopted for cultivation (Yoshimura et al., 2006). According to the trade statistics of the Ministry of Finance Japan, the amount of oilseed rape imported into Japan in 2006 was 2.27 million t, of which about $85.3 \%$ was imported from Canada, 14.7\% from Australia, and less than $0.004 \%$ each from Poland, France, and China. The commercial release of herbicide-resistant oilseed rape varieties in Australia was approved by the Office of the Gene Technology Regulator (OGTR) in 2003, but commercial planting of these varieties was not conducted until 2007 (USDA, 2008). 

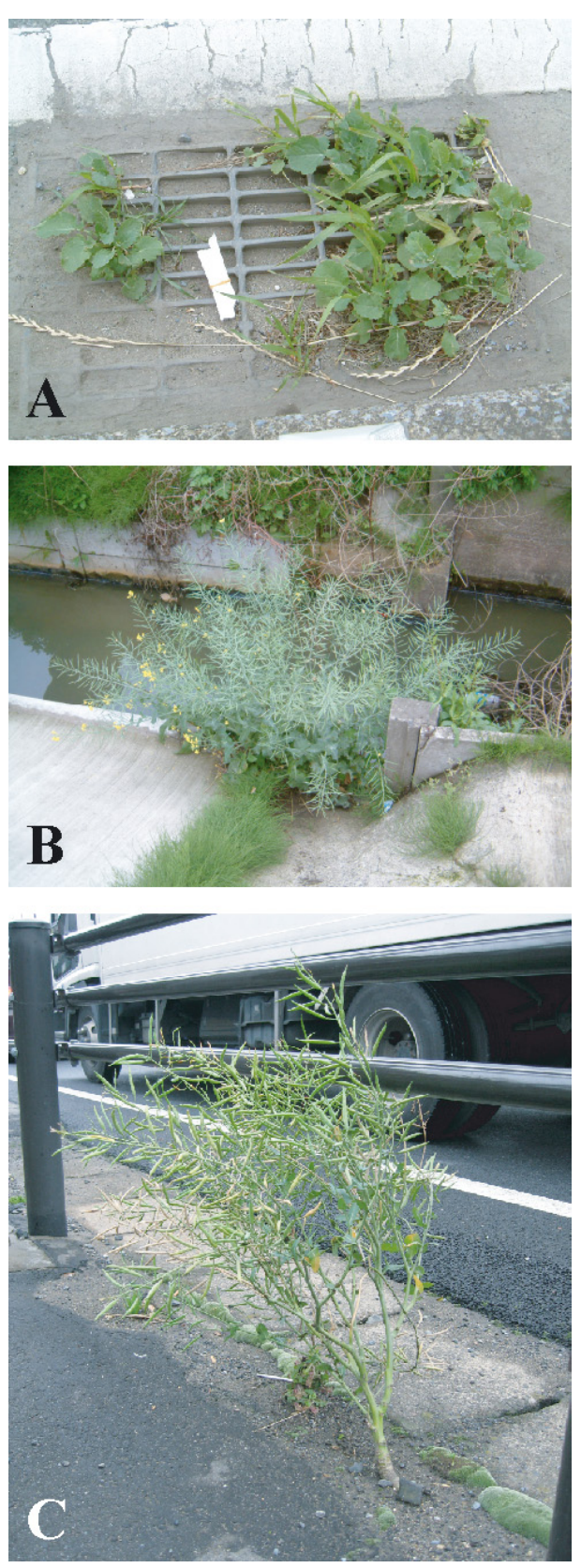

Figure 2. Oilseed rape (Brassica napus) plants that had taken root in various habitats along the roadside of Route 51. (A) Seedlings and juveniles in mud that accumulated in a drain. (B) Mature plant at the edge of the gutter. (C) Mature plant in chinks that formed between the cover of gutter and asphalt pavement.

Beckie et al. (2006) estimated that in 2005 over $80 \%$ of the oilseed rape area in Canada was devoted to herbicideresistant crops, most of which was the glyphosate- and glufosinate-tolerant varieties. Hence, it has been estimated that over $60 \%$ of the oilseed rape seeds imported into Japan have one of two herbicide-resistance genes (for glyphosate and glufosinate). However, the frequency of GM oilseed rape detected along Route 51 over the 3 -year period was very low. In addition to Kashima port, imported oilseed rape is discharged at 11 main ports in Japan, and herbicide-resistant oilseed rape has been detected at Chiba, Nagoya, Yokkaichi, Kobe, and 

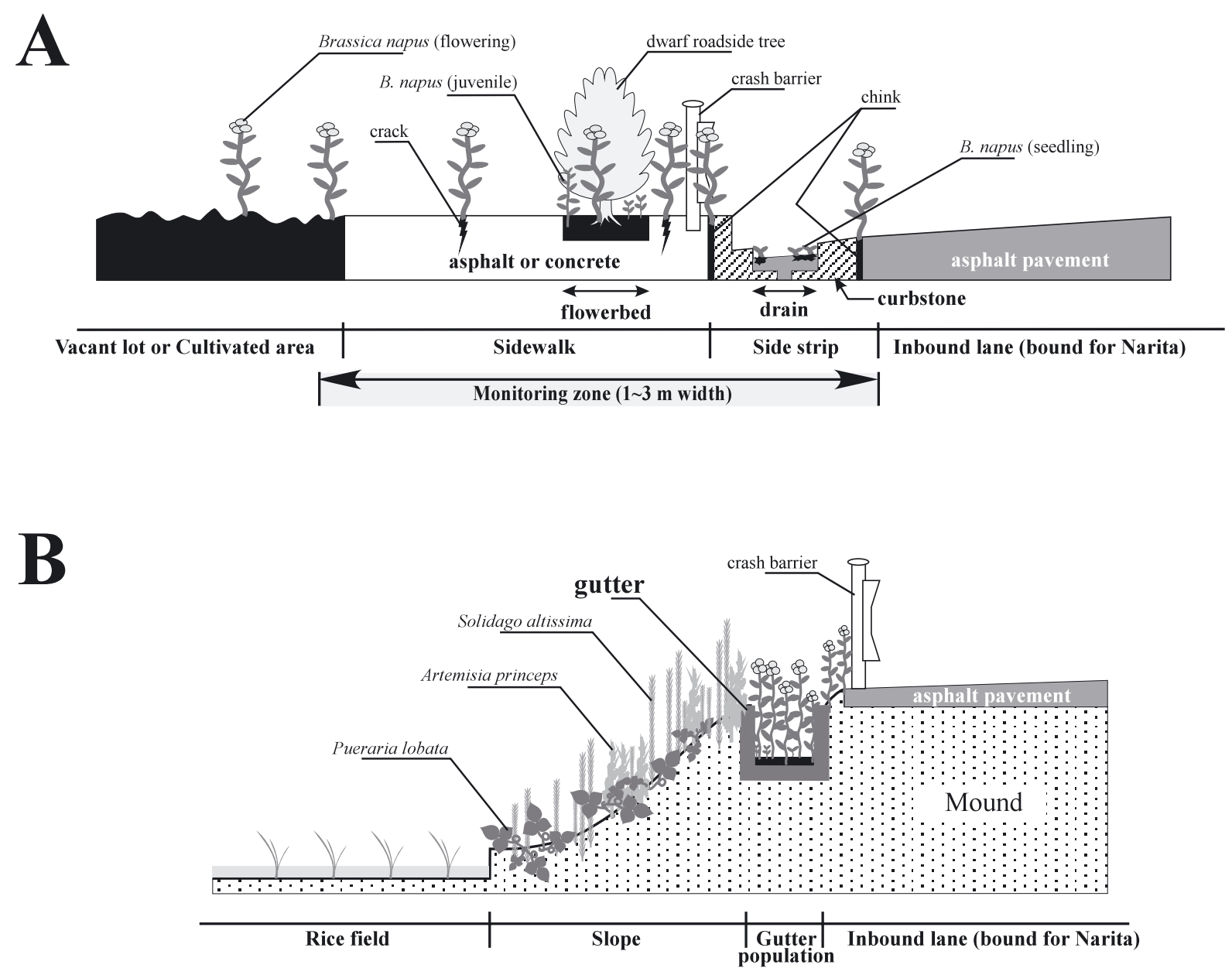

Figure 3. The sampling zone along the inbound lane of Route 51. Oilseed rape plants are indicated in green (figure in color available at http://www.ebr-journal.org). Matrix materials suitable for the growing of oilseed plants, such as the soil of flowerbeds, chinks and cracks in the pavement, accumulated mud in the gutter, and vacant lots or the edges of arable fields, are shaded black. (A) A representative roadside along Route 51. Concrete curbstones were buried along an asphalt pavement and drains were installed at intervals of several meters between them. A sidewalk was installed along the roadside strip on the far side of the strip from the asphalt pavement. Most oilseed rape plants were found growing in chinks that formed between the curbstones and the asphalt pavement and in cracks that arose within the sidewalk. Flowerbeds were installed along the sidewalk at intervals of several meters, and vacant lots or the edges of arable fields bordering on the sidewalk also served as habitat for a small number of plants. (B) Illustration of a gutter population that became established in segment \#15 of our survey route in 2006. At this location, the asphalt pavement of the road surface has been raised several meters above the surrounding fields for a distance of $300 \mathrm{~m}$. This part of Route 51 passes through a rice field, and a $30 \times 30-\mathrm{cm}$ gutter runs alongside the mound. The land slopes gently downward to the rice field from the edge of the gutter.

Hakata ports (Aono et al., 2006; JBCH, 2006). Explanations of the discrepancy between the occurrence of herbicide-resistant plants along Route 51 and the putative rate of GM oilseed rape within imports are that the imported oilseed rape that landed at Kashima port might have shifted to non-GM, or the nature of the oilseed rape transported along the road, such as its herbicideresistance traits, cultivar, or country of production, might have changed.
As our survey approached the center of Narita City, the number and frequency of glyphosate-resistant oilseed rapes tended to increase (Figs. 5A and 5B). Interestingly, although we detected a large number of plants in segment \#15 in 2006, no GM plants were found in this segment. Except for segments \#18 and \#20, the frequency of glyphosate-resistant plants in each segment was less than 0.2 (Fig. 5B). However, segments \#18 and \#20 tended to have higher frequencies of glyphosate-resistant plants. 


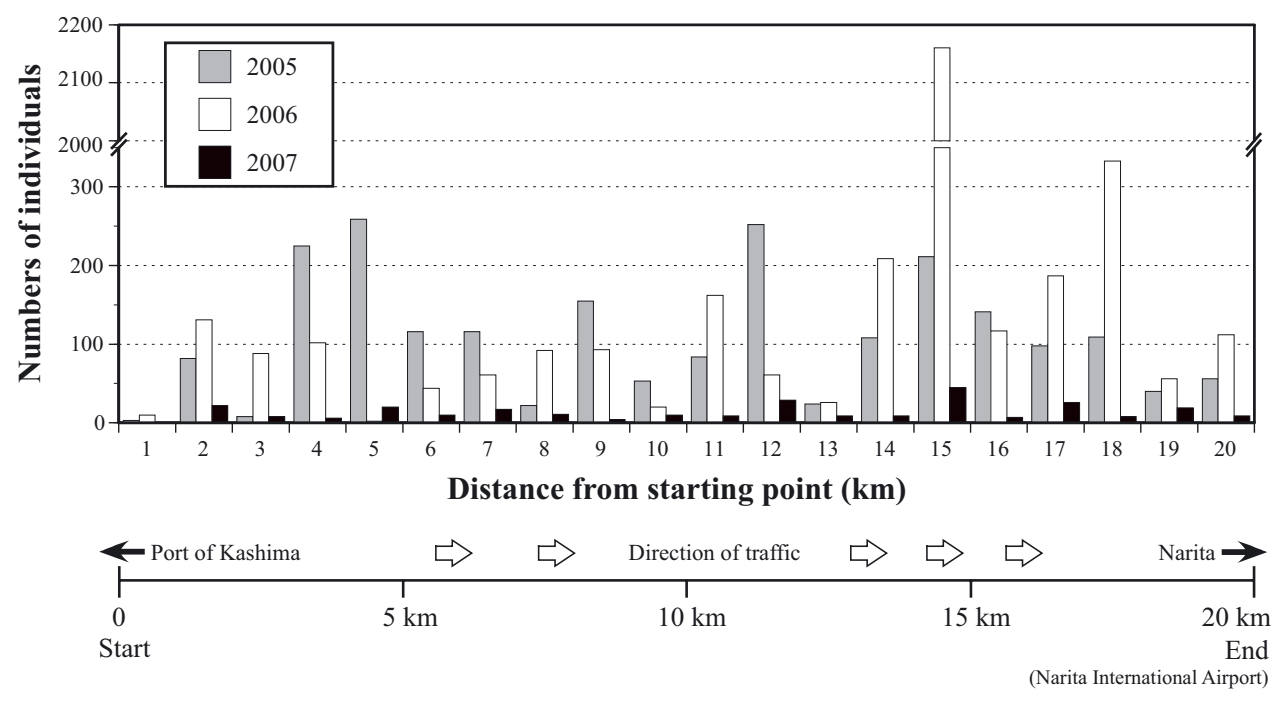

Figure 4. Numbers of oilseed rape plants found in each 1-km road segment. The segment numbers correspond to the distance from the starting point (Kitada, Fig. 1).

We have no information that would explain why the GM individuals appeared more often in these segments. However, this species can set self-compatible hermaphroditic flowers, in which self-pollination occasionally occurs (Cuthbert and McVetty, 2001; Rakow and Woods, 1987). Thus, if some B. napus GM individuals became established and self-pollination occurred, then they would be able to reproduce. This might permit the establishment of feral, herbicide-resistant individuals.

Our target zone for the sampling of oilseed rape ranged from 1 to $3 \mathrm{~m}$ in width, so the zone may include vacant lots and the edges of arable fields, and comprises flowerbeds at frequent intervals (Fig. 3A). Road cleaning using Unimog vehicles equipped with a rotating wire brush along the strip closest to the road is conducted by the Ministry of Land, Infrastructure, Transport and Tourism. Though most plants growing in the strip are removed by this cleaning, except some plants growing in drains or gutter bottoms, others might survive the road cleaning, particularly those in flowerbeds and vacant lots. Hence, reproduction of GM individuals in these refuge habitats may contribute to the growth of GM plants in certain zones, such as segment \#20, where the glyphosateresistant plants were detected in each of the three years. With the exception of segment \#20, the fluctuating appearance of GM plants during the three years could be attributed to variations in the content of GM seeds within the seed pool that spilled from transport vehicles, as the amount of GM seed in the cargoes may differ among transport vehicles.

Glufosinate-resistant plants were not detected again after their appearance in 2005 (Tab. 1, Fig. 5C). Because the number of these individuals was very low and was limited to only one year, we lack sufficient information to explain the fate of those individuals. However, there are some possible explanations for their disappearance. The male-sterility trait that was introduced into the glufosinate-resistant variety (Mariani et al., 1990) may have interfered with reproduction to a greater extent than in the glyphosate-resistant plants. However, in contrast to the state of the roadside habitats along Route 51, glufosinate-resistant oilseed rape plants frequently appeared in the Yokkaichi port area (Aono et al., 2006; JBCH, 2006). Hence, it is more likely that a shift in the nature of the imported oilseed rape would be the main cause of reduction in the glufosinateresistant plants. Multiple-herbicide-resistant oilseed rape plants, which possess both glyphosate- and glufosinateresistance genes, were not detected during the 3-year observations, although double-herbicide-resistant seeds had been detected in Yokkaichi area (Aono et al., 2006). To evaluate the fate of the glufosinate-resistant plants, further long-term demographic study and comparable research on the nature of the imported seeds within and among the region's ports will be needed.

\section{Provenance and environmental concern of oilseed rape plants found along Route $\mathbf{5 1}$}

Most of the roadside plants rooted in mud that accumulated in chinks between the asphalt and curbstones, but many also were growing in flowerbeds (Fig. 3A). The feral Brassica species that constitute the natural populations in Japan are mainly $B$. juncea Coss. and B. rapa $\mathrm{L}$. 

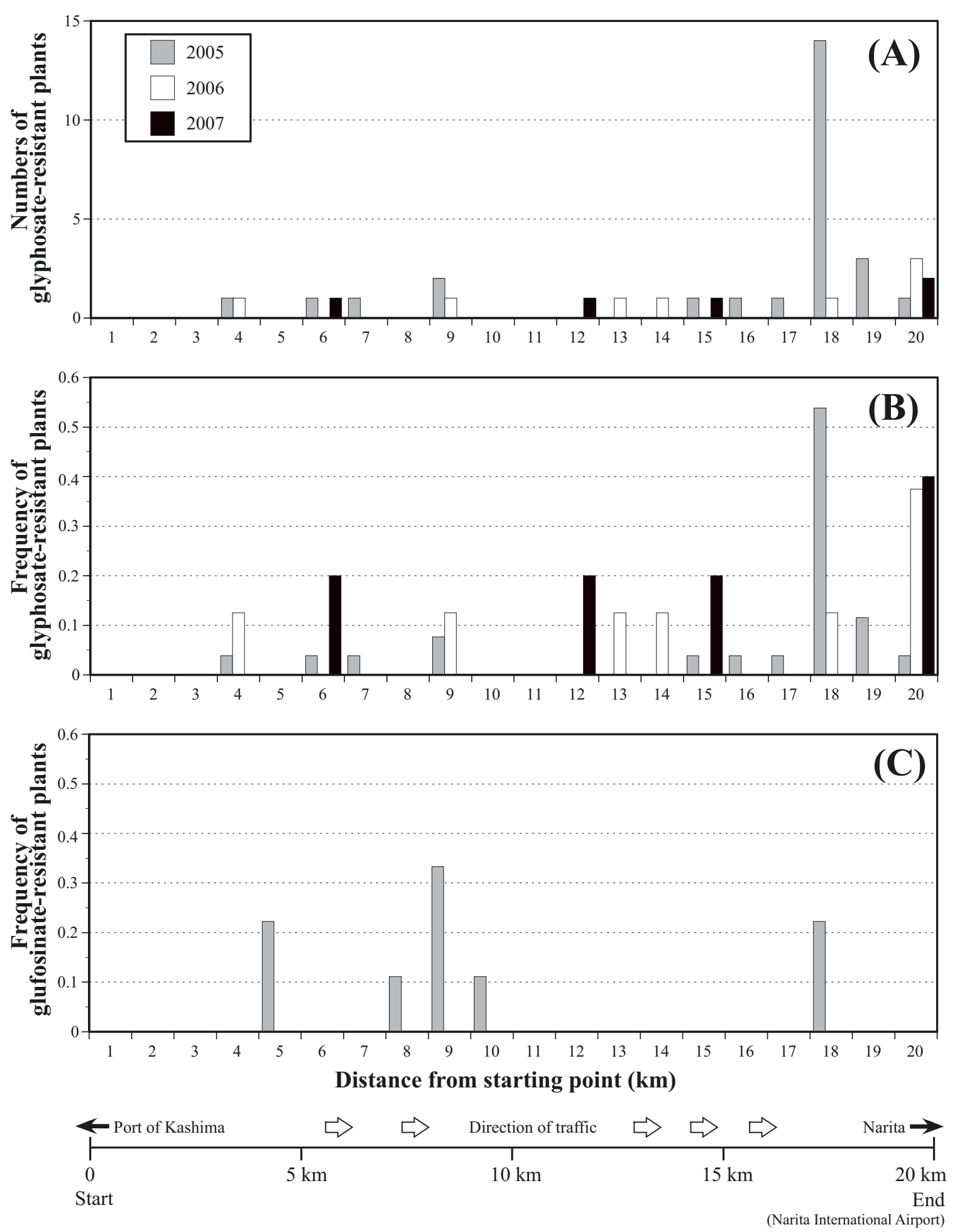

Figure 5. Transitions of herbicide-resistant oilseed rape plants that were detected along Route 51 from 2005 to 2007 . Numbers and frequencies of herbicide-resistant individuals in each 1-km segment of the road are shown. (A) Numbers of glyphosate-resistant individuals; (B) frequency of total plants that were glyphosate-resistant in each segment; (C) frequency of total plants that were glufosinate-resistant in each segment. The glufosinate-resistant plants were only detected in 2005. 
The distribution of B. napus in the Kashima area, where Route 51 passes through, is restricted to cultivated areas such as flowerbeds, sightseeing gardens, and fallow fields, although a few B. napus population have been observed in riverbanks in western Japan (Aono et al., 2006). A preliminary study that we conducted in 2004 revealed a few feral populations of $B$. napus along the monitoring route, and large feral populations of $B$. juncea were distributed along the riverbanks of the Tone River. Hence, there were few potential populations capable of supplying seeds of $B$. napus adjacent to the monitoring areas or north of the start of our monitoring. During our preliminary monitoring, however, oilseed rape plants along Route 51 were mainly found along the inbound lane (from Kashima to Narita). Such an asymmetrical distribution of oilseed rape plants between the two sides of the road was also reported by Crawley and Brown (2004) and von der Lippe and Kowarik (2007b). This evidence suggests that the oilseed rape plants found growing along Route 51 originated as seeds spilled from vehicles during transportation from the Port of Kashima into Keiyo District. The loss of seeds from vehicles would most often occur stochastically rather than systematically, thus the escape of GM seeds from loads of imported seeds would also occur by chance. If the seed spillage from the vehicles was arbitrary, then the distribution of the GM individuals would also be unsystematic, although the randomness of the distribution would be affected by potentially nonrandom variation in the presence of suitable seedbeds (e.g., the regular spacing of flowerbeds).

Although we cannot explain why the high-density population only appeared in the gutter of segment \#15 and only in 2006, massive expansion and persistence of feral oilseed rape populations along the monitoring zone were not detected during the three years. Moreover, the frequency of GM individuals among the oilseed rape plants detected along Route 51 was very low, and no spread of GM plants was detected around monitoring zone, at least during this observation period. These results are similar to those of a roadside survey along a cottonseed transport route in northeastern Australia, where Addison et al. (2007) searched for volunteer cotton (Gossypium hirsutum L.) plants along the 1400-km transport route. During the 3-year survey, they found 22 volunteer cotton plants outside the cotton production area, but only one of these plants was GM. More than $90 \%$ of the commercially released cotton in Australia is GM varieties (Addison et al., 2007). They concluded that current transportation practices in northeastern Australia presented negligible risk of establishment of naturalized GM or non-GM cotton populations along roadsides, because the density of volunteer cotton growing outside arable fields was low and they found no evidence of secondary spread.
On the other hand, some arable fields adjacent to Route 51 were used to cultivate brassicaceous vegetables, such as B. rapa (turnip and Chinese cabbage) or B. oleracea var. capitata L. (cabbage) and var. botrytis L. (broccoli). Some of these vegetables are left unharvested and flower in the following spring. Interspecific hybridization between Brassica crops can occur under natural conditions, although the results of hybridization potential differ among various reports (e.g., Chèvre et al., 2004; FitzJohn et al., 2007; Ford et al., 2006; Jørgensen et al., 1996; Légère, 2005; Sheffler and Dale, 1994; Stewart et al., 2003; Warwick et al., 2003; Wilkinson et al., 2003). Allainguillaume et al. (2006) reported that the fitness decline of hybrids between $B$. napus and B. rapa in the United Kingdom acted as a means of natural biological containment. However, the importation of brassicaceous vegetables in Japan is expected to increase, especially for cultivars of $B$. rapa from Asia. The short-term environmental impacts around Route 51 caused by oilseed spillage would be negligible. However, the effects of GM crops on the natural environment must be considered on a case-by-case basis (Chapman and Burke, 2006). For instance, Yokkaichi and Hakata ports, where GM oilseed rape plants already have been detected, would also be focal areas of environmental concern caused by escaped oilseed rape in Japan.

\section{CONCLUSION}

The occurrence of oilseed rape plants, including some GM individuals, was detected in each of the three years. Therefore, it seems that the spillage and loss of oilseed under the current transportation practices in Japan is unavoidable. However, by the end of the flowering season in 2007, we found no large populations of feral B. napus persisting within the monitoring zone and no sign of a fitness advantage of GM seeds. Moreover, conventional B. napus is not grown along the transportation route; thus, there is no concern about the co-existence of GM and non-GM oilseed rape cultivation around the monitoring zone adjacent to Route 51.

To perform a comprehensive risk assessment of oilseed rape seed spillage and loss, it is necessary to address the consequences of establishment, spread, and gene flow to wild relatives or crop species. Although herbicide-tolerance genes seem to be of minor environmental concern under the current circumstances around Route 51, the proportion of glyphosate-resistant individuals in 2007 was higher than in previous years. Thus, evaluating the effect of escaped transgenic oilseed rape plants on feral and domesticated Japanese brassicaceous plant species will require further long-term monitoring and comparative analysis among multiple monitoring sites. 


\section{MATERIALS AND METHODS}

\section{Monitoring site}

Route 51 is located in the eastern part of Japan's Kanto District. It begins at Chiba City, in Chiba Prefecture, and extends to Mito City, in Ibaraki Prefecture, for a total road length of $124 \mathrm{~km}$. The road passes south of Lake Kasumigaura along the route northeast from Chiba City to Mito City along the Sea of Kashima coast (Fig. 1). Kashima is one of the major ports in Kanto District, located south of Kashima City, and the Kashima coastal industrial region has developed around the port. Some of the cargoes discharged at the port of Kashima are transported to the capital region along Route 51.

We started our roadside survey at Kitada in Inashiki City, Ibaraki Prefecture, about $20 \mathrm{~km}$ west of the port of Kashima, where Route 51 crosses Route 125 . The roadside survey extended about $20 \mathrm{~km}$ from the starting point at Kitada to the tunnel that passes under the runway of Narita International Airport (Fig. 1). We surveyed the side of the road leading to Narita City to detect the presence of oilseed rape. The areas adjacent to the monitoring zone have various land-use types, including urban districts, arable areas, paddy fields, compost processing plants, and a steel bridge across the Tone River (the Suigo Bridge).

\section{Roadside survey and specimen collection}

The roadside surveys were carried out at the time of flowering of Brassica species, from mid-April to early-June, in 2005, 2006, and 2007. We performed the census of Brassica individuals and sampled their leaf materials on foot along the same stretch of road along Route 51 in all three years. The monitoring zone ranged in width from 1 to $3 \mathrm{~m}$ from the road edge, a zone that contained sidewalk, drains, and flowerbeds (Fig. 3A). Each individual was identified with a plastic tag that was attached to the plant root, and we recorded its position with respect to the nearest distance marker pole (established at $1-\mathrm{km}$ intervals along the road by the Ministry of Land, Infrastructure, Transport and Tourism) with a pedometer (a rotating wheel that is used to measure distances). To minimize measurement errors, we reset the pedometer at each distance marker.

We collected specimens of the leaves of each plant to test for herbicide resistance, as described in the next section. We collected about $5 \mathrm{~cm}^{2}$ of leaves from each plant. Some individuals matured extremely early, in which case we sampled fruits if insufficient leaves remained on the stem. Most Brassica plants growing in the monitoring zone were $B$. napus, but we also found some $B$. juncea. Identification of specimens as B. napus was based on morphological traits, such as the presence of amplexicaul or semi-amplexicaul leaves, entire or repand (irregularly wavy) leaf margins, a whitish leaf surface, and a large silicula compared with those of B. juncea or B. rapa.

\section{Detection of herbicide-resistance transgenes}

Collected leaves were lyophilized and stored in desiccators at room temperature. For our biochemical analyses by means of immunochemical chromatography, we homogenized $10 \mathrm{mg}$ of lyophilized leaves with a mortar and pestle in $200 \mu \mathrm{L}$ of distilled water and immunochemically analyzed the crude extracts to detect proteins that confer resistance to glyphosate (5-enolpyruvylshikimate-3-phosphate synthase, EPSPS; Comai et al., 1985) or glufosinate (phosphinothricin$\mathrm{N}$-acetyltransferase, PAT; Thompson et al., 1987) using the Reveal kit (Neogen, Lansing, MI, USA) and the TraitChek LL Test Kit (Strategic Diagnostic Inc., Newark, DE, USA), respectively.

For the DNA analyses, we homogenized $10 \mathrm{mg}$ of lyophilized leaves with a mortar and pestle in $400 \mu \mathrm{L}$ of phosphate-buffered saline (PBS) buffer $(137 \mathrm{mM}$ $\mathrm{NaCl}, 8.10 \mathrm{mM} \mathrm{Na} 2 \mathrm{HPO}_{4}, 2.68 \mathrm{mM} \mathrm{KCl}, 1.47 \mathrm{mM}$ $\mathrm{KH}_{2} \mathrm{PO}_{4}, \mathrm{pH}$ 7.4) and dropped the crude extracts on FTA Micro Cards (Whatman, Maidstone, Kent, UK). After desiccating the cards at room temperature for $48 \mathrm{~h}, 2$-mm-diameter discs were punched out. The discs were washed three times with TE $(10 \mathrm{mM}$ Tris-HCl, $1 \mathrm{mM}$ EDTA (ethylene diamine tetraacetic acid), $\mathrm{pH}$ 8.0) containing $0.5 \%$ sodium dodecyl sulfate and then three times with TE alone. Herbicide-resistance genes were analyzed by means of PCR with DNA from the discs used as the template. Nucleotide sequences of the primers were 5'-AAGAACTCCGTGTTAAGGAAAGCGA-3' and 5'-AGCCTTAGTGTCGGAGAGTTCGAT-3' for the cp4 epsps gene that encodes EPSPS, and 5'-ACAAGCACGGTCAACTTCCGTAC-3' and 5'-GAGCGCCTCGTGCATGCGCACG-3' for the bar gene that encodes PAT. Amplifications were carried out in $20-\mu \mathrm{L}$ reaction mixtures containing $1 \mathrm{X}$ PCR buffer, $2.5 \mathrm{mM} \mathrm{MgCl} 2,0.2 \mathrm{mM}$ of each dNTP, $1 \mu \mathrm{M}$ of each primer, and $1.5 \mathrm{U}$ rTaq polymerase (Toyobo Co., Ltd., Kita-ku, Osaka, Japan), with 30 cycles of denaturation at $94{ }^{\circ} \mathrm{C}$ for $1 \mathrm{~min}$, annealing for $2 \mathrm{~min}$ at 65 or $55^{\circ} \mathrm{C}$ for cp4 epsps and bar, respectively, and extension at $72{ }^{\circ} \mathrm{C}$ for $3 \mathrm{~min}$. PCR was performed in a GeneAmp PCR System 2720 Thermal cycler (Applied Biosystems, Foster City, CA, USA). The PCR-amplified products were then subjected to electrophoresis on $1.5 \%$ agarose gel. DNA bands of appropriate sizes were recovered from the gel, and their nucleotide sequences were determined using a DNA sequencer (ABI3730, Applied Biosystems) to confirm that these products corresponded to fragments 
of the respective genes. Final decision that the samples were the herbicide-resistance plants was based on the result of direct sequencing of the PCR products.

\section{ACKNOWLEDGEMENTS}

We thank the members of the Ecological Genetics Section of the National Institute for Environmental Studies (H. Watanabe, R. Nakazaki, Y. Otsuka, M. Nakajima, and H. Hashimoto) for their technical support.

Received July 24, 2008; accepted September 30, 2008.

\section{REFERENCES}

Addison SJ, Farrell T, Roberts GN, Rogers DJ (2007) Roadside surveys support predictions of negligible naturalisation potential for cotton (Gossypium hirsutum) in north-east Australia. Weed Res. 47: 192-201

Allainguillaume J, Alexander M, Bullock JM, Saunders M, Allender CJ, King G, Ford CS, Wilkinson MJ (2006) Fitness of hybrids between rapeseed (Brassica napus) and wild Brassica rapa in natural habitats. Mol. Ecol. 15: 11751184

Aono M, Wakiyama S, Nagatsu M, Nakajima N, Tamaoki M, Kubo A, Saji H (2006) Detection of feral transgenic oilseed rape with multiple-herbicide resistance in Japan. Environ. Biosafety Res. 5: 77-87

Beckie HJ, Harker KN, Hall LM, Warwick SI, Légère A, Sikkema PH, Clayton GW, Thomas AG, Leeson JY, Séguin-Swartz G, Simard M-J (2006) A decade of herbicide-resistant crops in Canada. Can. J. Plant Sci. 86: 1243-1264

Chapman MA, Burke JM (2006) Letting the gene out of the bottle: the population genetics of genetically modified crops. New Phytol. 170: 429-443

Chèvre AM, Ammitzbøll H, Breckling B, Dietz-Pfeilstetter A, Eber F, Fargue A, Gomez-Campo C, Jenczewski E, Jørgensen R, Lavigne C, Meier M, den Nijs H, Pascher K, Seguin-Swartz G, Sweet J, Stewart N, Warwick S (2004) A Review on Interspecific Gene Flow from Oilseed Rape to Wild Relatives. In Den Nijs HCM, Bartsch D, Sweet J, eds, Introgression from Genetically Modified Plants into Wild Relatives, CABI Publishing, Cambridge, pp 235-251

Comai L, Facciotti D, Hiatt WR, Thompson G, Rose RE, Stalker DM (1985) Expression in plants of a mutant aroA gene from Salmonella typhimurium confers tolerance to glyphosate. Nature 317: 741-744

Crawley MJ, Brown SL (1995) Seed limitation and the dynamics of feral oilseed rape on the M25 motorway. Proc. Roy. Soc. London B 259: 49-54
Crawley MJ, Brown SL (2004) Spatially structured population dynamics in feral oilseed rape. Proc. Roy. Soc. London B 271: 1909-1916

Cuthbert JL, McVetty PBE (2001) Plot-to-plot, row-to-row and plant-to-plant outcrossing studies in oilseed rape. Can. J. Plant Sci. 81: 657-664

FitzJohn RG, Armstrong TT, Newstrom-Lloyd LE, Wilton AD, Cochrane M (2007) Hybridisation within Brassica and allied genera: evaluation of potential for transgene escape. Euphytica 158: 209-230

Ford CS, Allainguillaume J, Grilli-Chantler P, Cuccato G, Allender CJ, Wilkinson MJ (2006) Spontaneous gene flow from rapeseed (Brassica napus) to wild Brassica oleracea. Proc. Roy. Soc. London B 273: 3111-3115

Gray AJ, Raybould AF (1998) Reducing transgene escape routes. Nature 392: 653-654

Gruber S, Pekrun C, Claupein W (2004) Population dynamics of volunteer oilseed rape (Brassica napus L.) affected by tillage. Eur. J. Agron. 20: 351-361

Hodkinson DJ, Thompson K (1997) Plant dispersal: the role of man. J. Appl. Ecol. 34: 1484-1496

ISAAA (International Service for the Acquisition of Agribiotech Applications) (2006) ISAAA Briefs 34-2005: Global Status of Commercialized Biotech/GM Crops: 2005. Available at http://www.isaaa.org/

ISAAA (International Service for the Acquisition of Agribiotech Applications) (2007) ISAAA Briefs 37-2007: Global Status of Commercialized Biotech/GM Crops: 2007. Available at http://www.isaaa.org/

JBCH (Japan Biosafety Clearing House) (2006) Report of the Risk Monitoring of Genetically Modified Organisms (oilseed rape) (in Japanese). Available at http://www.bch.biodic.go.jp/ natane_1.html

Jørgensen RB, Andersen B, Landbo L, Mikkelsen TR (1996) Spontaneous hybridization between oilseed rape (Brassica napus) and weedy relatives. Acta Hortic. 407: 193-200

Légère A (2005) Risks and consequences of gene flow from herbicide-resistant crops: canola (Brassica napus L) as a case study. Pest Manage. Sci. 61: 292-300

Lu B-R (2008) Transgene Escape from GM Crops and Potential Biosafety Consequences: An Environmental Perspective, ICGEB Collection of Biosafety Reviews. Available at http:// www.icgeb.org/ bsafesrv/publications/vol4.html

Lutman PJW (1993) The occurrence and persistence of volunteer oilseed rape (Brassica napus). Asp. Appl. Biol. 35: 29-36

Mariani C, de Beuckeleer M, Truettner J, Leemans J, Goldberg RB (1990) Induction of male sterility in plants by a chimaeric ribonuclease gene. Nature 347: 737-741

Pessel FD, Lecomte J, Emeriau V, Krouti M, Messean A, Gouyon PH (2001) Persistence of oilseed rape (Brassica napus L.) outside of cultivated fields. Theor. Appl. Genet. 102: 841-846 
Rakow G, Woods DL (1987) Outcrossing in rape and mustard under Saskatchewan prairie conditions. Can. J. Plant Sci. 67: $147-151$

Saji H, Nakajima N, Aono M, Tamaoki M, Kubo A, Wakiyama S, Hatase Y, Nagatsu M (2005) Monitoring the escape of transgenic oilseed rape around Japanese ports and roadsides. Environ. Biosafety Res. 4: 217-222

Scheffler JA, Dale PJ (1994) Opportunities for gene transfer from transgenic oilseed rape (Brassica napus) to related species. Transgen. Res. 3: 263-278

Snow AA, Andow DA, Gepts P, Hallerman EM, Power A, Tiedje JM, Wolfenbarger LL (2005) Genetically engineered organisms and the environment: current status and recommendations. Ecol. Appl. 15: 377-404

Stewart CN Jr (2005) Monitoring the presence and expression of transgenes in living plants. Trends Plant Sci. 10: 390-396

Stewart CN Jr, Halfhill MD, Warwick SI (2003) Transgenic introgression from genetically modified crops to their wild relatives. Nat. Rev. Genet. 4: 806-817

Thompson CJ, Movva NR, Tizard R, Crameri R, Davies JE, Lauwereys M, Botterman J (1987) Characterization of the herbicide-resistance gene bar from Streptomyces hygroscopicus. EMBO J. 6: 2519-2523

USDA (United States Department of Agriculture) (2008) USDA Foreign Agricultural Service, Global Agriculture Information Network Report,
Australia Biotechnology Agricultural Biotechnology Annual Report 2008, GAIN Report Number AS8035. Available at http://www.fas.usda.gov/gainfiles/200807/146295182.pdf

von der Lippe M, Kowarik I (2007a) Long-distance dispersal of plants by vehicles as a driver of plant invasions. Conserv. Biol. 21: 986-996

von der Lippe M, Kowarik I (2007b) Crop seed spillage along roads: a factor of uncertainty in the containment of GMO. Ecography 30: 483-490

Warwick SI, Simard M-J, Légère A, Beckie HJ, Braun L, Zhu B, Mason P, Séguin-Swartz G, Stewart CN (2003) Hybridization between transgenic Brassica napus L. and its wild relatives: Brassica rapa L., Raphanus raphanistrum L., Sinapis arvensis L., and Erucastrum gallicum (Willd.) O. E. Schulz. Theor. Appl. Genet. 107: 528-539

Wilkinson MJ, Elliott LJ, Allainguillaume J, Shaw MW, Norris C, Welters R, Alexander M, Sweet J, Mason DC (2003) Hybridization between Brassica napus and B. rapa on a national scale in the United Kingdom. Science 302: 457-459

Yoshimura Y, Beckie HJ, Matsuo K (2006) Transgenic oilseed rape along transportation routes and port of Vancouver in western Canada. Environ. Biosafety Res. 5: 67-75

Zwaenepoel A, Roovers P, Hermy M (2006) Motor vehicles as vectors of plant species from road verges in a suburban environment. Basic Appl. Ecol. 7: 83-93 